\title{
Evaluation of olive oil mill wastewater toxicity on the mitochondrial bioenergetics after treatment with Candida oleophila
}

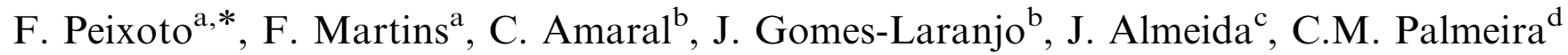 \\ ${ }^{a}$ Chemistry Department, CECAV, University of Trás-os-Montes and Alto Douro, 5001 Vila Real, Portugal \\ ${ }^{\mathrm{b}}$ Department of Biology and Environmental Engineering, CETAV, University of Trás-os-Montes and Alto Douro, 5001 Vila Real, Portugal \\ ${ }^{\mathrm{c}}$ Department of Veterinary Sciences, CECAV, University of Trás-os-Montes and Alto Douro, 5001 Vila Real, Portugal \\ ${ }^{\mathrm{d}}$ Mitochondrial Research Group, IMAR, Department of Zoology, University of Coimbra, 3004-517 Coimbra, Portugal
}

Received 24 July 2007; received in revised form 1 November 2007; accepted 15 November 2007

Available online 11 February 2008

\begin{abstract}
In a previous work the ability of Candida oleophila to use phenolic compounds as sole carbon and energy source at high concentrations without an additional carbon source was reported. C. oleophila grown in bioreactor batch cultures in a diluted and sterilized olive oil mill wastewater (OMW) caused a significant decrease in the total tannins content but no significant alteration was observed in phenolic acid and fatty acid content. Both treated and untreated OMWs were tested to evaluate the capacity in interfering with mitochondrial bioenergetics. Mitochondrial respiration was not affected by treated OMW on the range of used concentrations, contrary to the untreated OMW. Furthermore, mitochondrial membrane potential and respiratory complexes were always significantly less affected by treated OMW in comparison with untreated OMW. However, supplementary treatment should be applied before OMW could be considered non-toxic.
\end{abstract}

(C) 2007 Elsevier Inc. All rights reserved.

Keywords: Olive mill wastewaters; Yeasts; Polyphenols; Tannins; Fatty acid; Biodegradation; Acute toxicity; Mitochondria; Bioenergetics

\section{Introduction}

The growing consumer demand for olive oil, as a consequence of its proved benefits for human health (Tuck and Hayball, 2002), has become a positive factor for higher productions of this natural fat. Olive oil extraction industries are mainly located in Mediterranean countries, producing seasonally large amounts of black olive wastewaters generally referred as olive mill wastewaters (OMWs). The amount of OMW produced is dependent on the extraction process used. In general, for each ton of olives processed, $1.3 \mathrm{~m}^{3}$ of black waters are produced (Vitolo et al., 1999). This black liquid wastewater is highly pollutant, since it presents high biological oxygen demand

Abbreviations: OMW, olive mill wastewater; FCCP, carbonylcyanide p-trifluoromethoxyphenylhydrazone; BSA, bovine serum albumin; EGTA, ethyleneglycol-bis( $\beta$-aminoethyl ether) $N, N, N^{\prime}, N^{\prime}$-tetraacetic acid;

EDTA, ethylene-diaminetetraacetic; TPP ${ }^{+}$, tetraphenylphosphonium.

${ }^{*}$ Corresponding author. Fax: + 351259320480.

E-mail address: fpeixoto@utad.pt (F. Peixoto).
(BOD) values $\left(50-100 \mathrm{gO}_{2} / \mathrm{L}\right)$ as well as chemical oxygen demand (COD) values $\left(80-200 \mathrm{gO}_{2} / \mathrm{L}\right.$ ) (Khoufi et al., 2006). These are 200-400 times higher than those of a typical municipal sewage (Cossu et al., 1993). Besides its high organic loading, the presence of polyphenols and tannins, high content of suspended solids, and acidity make these waters highly recalcitrant to conventional water treatment making the management and disposal of olive oil mill effluents a serious environmental problem (Paixão et al., 1999).

The research on OMW valorization has been focused on the degradation/elimination of phenolic compounds, since their breakdown is considered as the limiting step on the biotreatment of OMW (Fountoulakis et al., 2002). Therefore many different methods have already been proposed to decompose OMW (Aggelis et al., 2003; Benitez et al., 1999, 1997; Fadil et al., 2003; Gotsi et al., 2005; Pinto et al., 2002). In several of these works, microorganisms like filamentous fungi have been used to pre-treat OMW, since many are able to reduce polyphenol contents, making these 
waters suitable for secondary conventional treatment (Fadil et al., 2003).

Several investigations have already been carried out to evaluate OMW toxicity on microorganisms (Paixão et al., 1999). These clearly show that OMWs are highly toxicant not only to microorganisms but also to microcrustaceans as Daphnia magna or Tamnocephalus platyurus although the parameter responsible for this toxicity was not clear.

Furthermore, Sert et al. (1998) have shown that ferulic acid, a phenolic acid frequent in OMW, carries out an interference with both L-malate dehydrogenase and malic enzyme. Our previous studies have shown that mitochondrial bioenergetics is strongly disturbed by OMW (Martins et al., 2007). Interference with mitochondrial bioenergetics is known to be a part of the process of cell injury by assorted agents and by a variety of mechanisms (Wallace et al., 1997). Mitochondrial dysfunction promoted by any toxicant can lead to apoptotic cell death and to some neuronal degenerative diseases (Eckert et al., 2003). Furthermore, mitochondrion has proved itself to be a good model to study the action of many xenobiotics on cell toxicity, since data obtained from such studies are generally well correlated with cytotoxicity parameters reported in cell cultures and whole organisms (Knobeloch et al., 1990).

Filamentous fungi like Geotrichum sp., Aspergillus sp., Pleurotus sp., or Phanerochaete sp. have proved to be efficient in eliminating some organic loading and phenolic fractions of OMW (Borja et al., 1995a, b; Gharsallah et al., 1999). Yeasts are mainly unicellular fungi, which when used in full-scale wastewater plants do not present the bulking problems associated with filament formation. Besides, in previous works (Amaral et al., 2005), yeasts isolated by our working group, belonging to genus Candida, have shown the ability to use phenolic compounds as sole carbon and energy source at high concentrations $(1000 \mathrm{mg} / \mathrm{L})$. Based on these previous results, and considering the problem of technology application at large scale, the aim of this study was to evaluate the ability of Candida oleophila to remove phenolic and other toxic compounds from a real olive mill effluent, and analyse the effect of this biodegradation on the mitochondrial bioenergetics using isolated mitochondria from rat liver.

\section{Materials and methods}

\subsection{Isolation of rat liver mitochondria}

Wistar rats $(200-300 \mathrm{~g})$ were fasted overnight before being killed by cervical displacement. The isolation was performed by conventional methods (Gazzoti et al., 1979) with minor modifications. The homogenization medium contained $0.25 \mathrm{M}$ sucrose, $5 \mathrm{mM}$ Hepes ( $\mathrm{pH} 7.4$ ), $0.2 \mathrm{mM}$ EGTA, and $0.1 \%$ fatty acid-free bovine serum albumin (BSA). EGTA and BSA were omitted from the final washing medium, which was adjusted to $\mathrm{pH}$ 7.2. The final concentration of the mitochondrial protein was determined by the biuret method (Gornall et al., 1949) using BSA as standard. The experiments were carried out in accordance with the
National Requirements for Vertebrate Animal Research and European Convention for the Protection of Animals Used for Experimental and Other Scientific Purposes.

\subsection{OMW used}

Samples of OMWs were collected from a continuous olive mill located in Northeastern Portugal during 2005-2006 extraction campaign. The samples were collected in order to obtain a representative effluent of the entire labouring period (December-February). After collection, samples were analysed for $\mathrm{pH}, \mathrm{DO}$, and temperature, in situ, using a multiparameter analyser Model 210i from WTW according to manufacturers' instructions. For biological treatment, samples were diluted with deionized water $(75 \% \mathrm{v} / \mathrm{v})$ and sterilized at $121^{\circ} \mathrm{C}$ for $15 \mathrm{~min}$. Sterilization was performed in order to ensure that biological treatment was made only by inoculated Candida strains. Hundred millilitre aliquots were aseptically collected at regular intervals and stored deep frozen $\left(-70^{\circ} \mathrm{C}\right)$. To perform the toxicological evaluation, the samples were defrosted, centrifuged at $8.000 \mathrm{rpm}$ at $4{ }^{\circ} \mathrm{C}$ during $15 \mathrm{~min}$. The $\mathrm{pH}$ was adjusted to 7.0 with $\mathrm{NaOH}$ $(2 \mathrm{M})$. In each toxicological evaluation, concentrations of $0.5 \%, 1.0 \%$, $1.5 \%$, and $2.0 \%(\mathrm{v} / \mathrm{v})$ of treated and untreated OMWs were prepared with each respective reaction medium.

\subsection{Microorganisms}

Pure young cultures of $C$. oleophila were prepared in Petri dishes with YM Agar from Difco ${ }^{\circledR}$. Plates were incubated for $48 \mathrm{~h}$ at $28^{\circ} \mathrm{C}$ and inoculated in Erlenmeyer flasks containing $500 \mathrm{~mL}$ of sterilized and previously diluted OMW. Inoculum was made at $1 \% \mathrm{v} / \mathrm{v}$ when in active growing phase $\left(A_{640 \mathrm{~nm}} \approx 1.0\right)$. Samples were made in duplicate with Erlenmeyer flasks with no inoculum which served as blanks.

\subsection{Phenols assimilation assays}

The reactors prepared as above were incubated at $28^{\circ} \mathrm{C}$, in an orbital shaker at $120 \mathrm{rpm}$, in order to ensure aerobic conditions in the reactors. After a 30 day incubation period, samples were aseptically collected for analysis. Samples for toxicological surveillance were collected in $100 \mathrm{~mL}$ polypropylene containers and stored deep frozen until analysis. Simultaneously $1 \mathrm{~mL}$ aliquots were aseptically collected in sterilized Eppendorf vessels for chromatographic analysis.

\subsection{Phenolic acids analysis}

Phenolic assimilation by yeasts was monitored by reverse-phase highperformance liquid chromatography (RP-HPLC). HPLC analysis was performed with a $\mathrm{C} 18$ column $(150 \times 4.6 \mathrm{~mm})$ Hipersyl using gradient elution. The gradient was made as follows: $0-3 \mathrm{~min} 100 \%$ of A (water, methanol, and acetic acid, 88:10:2), 3-6 min $80 \%$ of $\mathrm{A}$ and $20 \%$ of $\mathrm{B}$ (water, methanol, 70:30), 6-9 min $60 \%$ of $\mathrm{A}$ and $40 \%$ of $\mathrm{B}, 9-12 \mathrm{~min}$ $100 \%$ of B, $12-30 \mathrm{~min} 100 \%$ of A. Detection was performed at $265 \mathrm{~nm}$ in a Merck-Hitachi L-4000 UV detector. The identification of phenol retention times was made by external standard's method.

\subsection{Condensed tannin analysis}

The tannins were determined by UV spectrophotometry method (Cary 50-Varian) based on acid hydrolysis and colour formation (Porter, 1986). Five hundred microlitres of the OMW was used for analysis with $1 \mathrm{~mL}$ of $n$-butanol $\pm \mathrm{HCl}$ solution $(95: 5, \mathrm{v} / \mathrm{v})$ and $40 \mu \mathrm{L}$ of the iron reagent $(2 \%$ ferric ammonium sulphate in $2 \mathrm{~N} \mathrm{HCl})$. For control samples, $500 \mu \mathrm{L}$ of distilled water was used. The test tubes were covered with glass marbles and heated at $95^{\circ} \mathrm{C}$ for $1 \mathrm{~h}$ using a heating block. The test tubes were cooled to room temperature, centrifuged, and absorbance measured at $550 \mathrm{~nm}$. 


\subsection{Fatty acid analysis}

OMW free fatty acids were analysed by gas chromatography according to Procida (Procida and Ceccon, 2006) with slight modifications. Samples (15 mL) were gushed by $\mathrm{N}_{2}$ and the $\mathrm{pH}$ was adjusted to 2-3 with phosphoric acid. Acetone was added to the sample (water/acetone 1:2, v/v) and $0.1 \mathrm{~g}$ of polyvynilpirrolidone (PVP) to eliminate the interference by phenolic compounds. After 30-min incubation, the sample was clarified by centrifugation. Free fatty acids were analysed with a Perkin-Elmer gas chromatograph adapted for capillary columns. A FFAP-DB fused-silica capillary column, $30 \mathrm{~m} \times 0.53 \mathrm{~mm}$ ID $\times 1 \mu \mathrm{m}$ film thickness, was used. Oven temperature was programmed from 70 to $200^{\circ} \mathrm{C}$ at $4{ }^{\circ} \mathrm{C} / \mathrm{min}$, then from 200 to $240^{\circ} \mathrm{C}$ at $4{ }^{\circ} \mathrm{C} / \mathrm{min}$. Detector temperature was $260^{\circ} \mathrm{C}$; carrier gas (helium) flow rate, $2.0 \mathrm{~mL} / \mathrm{min}$. Peak heights were calculated using an appropriate integration software (JCL 6000 chromatography data system).

\subsection{Mitochondrial respiratory activity}

Oxygen consumption of isolated mitochondria was measured polarographically at $30^{\circ} \mathrm{C}$ with a Clark oxygen electrode, in a closed chamber with magnetic stirring. The reaction medium consisted of $250 \mathrm{mM}$ sucrose, $20 \mathrm{mM} \mathrm{KCl}, 2 \mathrm{mM} \mathrm{MgCl}, 5 \mathrm{mM} \mathrm{KH}_{2} \mathrm{PO}_{4}$, and $5 \mathrm{mM}$ Hepes (pH 7.2). OMW was added in aliquots $(0-20 \mu \mathrm{L})$ to $1 \mathrm{~mL}$ of the standard respiratory medium $\left(25^{\circ} \mathrm{C}\right)$ with mitochondria $(1 \mathrm{mg}$ protein), supplemented with $2 \mu \mathrm{M}$ rotenone and allowed to incubate for $10 \mathrm{~min}$ before the addition of $10 \mathrm{mM}$ succinate. State 4 respiration was achieved after phosphorylation of $50 \mathrm{nmol}$ adenosine diphosphate (ADP). State 3 was elicited by adding adenosine $5^{\prime}$-diphosphate (ADP; $1 \mathrm{mM}$ ), and uncoupled respiration, by adding $1 \mu \mathrm{M}$ FCCP. Controls were made as above with minor changes: first we exposed the mitochondria to a medium preimplemented with substrate and added OMW $5 \mathrm{~min}$ later. The purpose of this control was to verify whether the mitochondria preincubated with OMW prior to substrate addition resulted in an irreversible damage on the respiratory complexes, with a limitation in the maximal respiratory rates.

\subsection{Membrane potential}

The mitochondrial transmembrane potential $(\Delta \psi)$ was measured indirectly based on the activity of the lipophilic cation tetraphenylphosphonium $\left(\mathrm{TPP}^{+}\right)$using a $\mathrm{TPP}^{+}$-selective electrode in combination with and $\mathrm{Ag} / \mathrm{AgCl}$-saturated reference electrode, as previously described (Peixoto, 2005). Mitochondria (1 mg protein) were incubated in $1 \mathrm{~mL}$ of medium containing $250 \mathrm{mM}$ sucrose, $20 \mathrm{mM} \mathrm{KCl}, 2 \mathrm{mM} \mathrm{MgCl}_{2}, 5 \mathrm{mM}$ $\mathrm{KH}_{2} \mathrm{PO}_{4}$, and $5 \mathrm{mM}$ Hepes ( $\mathrm{pH} 7.2$ ), supplemented with $2 \mu \mathrm{M}$ rotenone and $3 \mu \mathrm{M} \mathrm{TPP}{ }^{+}$and energized with $10 \mathrm{mM}$ succinate. No correction was made for the "passive" binding of $\mathrm{TPP}^{+}$to the mitochondria membranes because the purpose of the experiments was to show relative changes in potential rather than absolute values. As a consequence, we can anticipate some overestimation for the values.

\subsection{Enzymatic activities}

Succinate dehydrogenase activity was measured spectrophotometrically by the reduction of 2,6-dichlorophenolindophenol (DCIP) at $600 \mathrm{~nm}$ in the presence of phenazine methosulfate (PMS) (Singer, 1974). The reaction was performed in $1 \mathrm{~mL}$ of the standard reaction medium supplemented with $5 \mathrm{mM}$ succinate, $2 \mu \mathrm{M}$ rotenone, $0.1 \mu \mathrm{g}$ antimycin $\mathrm{A}, 1 \mathrm{mM} \mathrm{KCN}$, $0.025 \%$ Triton $\mathrm{X}-100$ at $25^{\circ} \mathrm{C}$, and $0.5 \mathrm{mg}$ protein of disrupted mitochondria (two cycles of freezing and thawing).

Succinate cytochrome $c$ reductase activity was measured spectrophotometrically (Tisdale, 1967) at $25^{\circ} \mathrm{C}$ by following the reduction of oxidized cytochrome $c$ by the increase in absorbance at $550 \mathrm{~nm}$. The reaction was initiated by the addition of $5 \mathrm{mM}$ succinate to $3 \mathrm{~mL}$ of the standard reaction medium supplemented with $2 \mu \mathrm{M}$ rotenone,
$1 \mathrm{mM} \mathrm{KCN}, 54 \mu \mathrm{M}$ of cytochrome c, and $0.3 \mathrm{mg}$ protein of broken mitochondria.

Cytochrome $c$ oxidase activity was measured polarographically (Brautigan et al., 1978) at $25^{\circ} \mathrm{C}$ in $1 \mathrm{~mL}$ of the standard reaction medium supplemented with $5 \mathrm{mM}$ succinate, $2 \mu \mathrm{M}$ rotenone, $10 \mu \mathrm{M}$ cytochrome c, and $0.5 \mathrm{mg}$ protein broken mitochondria. The reaction was initiated by the addition of $5 \mathrm{mM}$ ascorbate plus $0.25 \mathrm{mM}$ TMPD.

ATP-synthase activity was determined by monitoring the $\mathrm{pH}$ increase associated with ATP synthesis (Madeira et al., 1974). The reaction was carried out in $2 \mathrm{~mL}$ of the reaction medium containing $130 \mathrm{mM}$ sucrose, $50 \mathrm{mM} \mathrm{KCl}, 5 \mathrm{mM} \mathrm{MgCl}$, and $2 \mathrm{mM} \mathrm{KH}_{2} \mathrm{PO}_{4}$ (pH 7.2), supplemented with $5 \mathrm{mM}$ succinate and $1 \mathrm{mg}$ of mitochondrial protein. The reaction was initiated by the addition of $200 \mu \mathrm{M}$ ADP to the mitochondrial suspension. The $\mathrm{pH}$ change was evaluated with a Crison $\mathrm{pH}$ meter connected to a Hansatech acquisition data system. The addition of oligomycin $(2 \mu \mathrm{g} / \mathrm{mg}$ protein) completely halted $\mathrm{H}^{+}$consumption. $\mathrm{H}^{+}$consumption was calculated after an elapsed time of $2 \mathrm{~min}$ from the start of the reaction.

ATPase activity was determined by monitoring the $\mathrm{pH}$ change associated with ATP hydrolysis (Madeira et al., 1974). The reaction was carried out in $2 \mathrm{~mL}$ of a medium containing $130 \mathrm{mM}$ sucrose, $50 \mathrm{mM} \mathrm{KCl}$, $5 \mathrm{mM} \mathrm{MgCl}_{2}$, and $0.5 \mathrm{mM}$ Hepes (pH 7.2), supplemented with $2 \mu \mathrm{M}$ rotenone and mitochondria (1 $\mathrm{mg}$ protein of disrupted mitochondria). The reaction was initiated by the addition of $2 \mathrm{mM}$ Mg-ATP and was completely inhibited by the addition of oligomycin $(2 \mu \mathrm{g} / \mathrm{mg}$ mitochondrial protein); this means that activity measured is due to a mitochondrial $\mathrm{F}_{0}-\mathrm{F}_{1}$ ATPase which is an $\mathrm{Mg}^{2+}$ ATPase. Proton production was again calculated 2 min after starting the reaction.

\subsection{Mitochondrial swelling}

Mitochondrial osmotic swelling was estimated from the decrease in the absorbance at $520 \mathrm{~nm}$, measured in a UV/VIS spectrophotometer lambda 45 , with magnetic stirring and thermostatic chamber $\left(25^{\circ} \mathrm{C}\right)$ Reaction medium contained $54 \mathrm{mM} \mathrm{K}^{+}$-acetate, $5 \mathrm{mM} \mathrm{HEPES-Na}{ }^{+}$ buffer, $\mathrm{pH}$ 7.2, $0.1 \mathrm{mM}$ EGTA, $0.2 \mathrm{mM}$ EDTA, $15 \mu \mathrm{M}$ atractyloside, $1 \mu \mathrm{M}$ antimycin $\mathrm{A}, 100 \mu \mathrm{M} \mathrm{Na}{ }^{+}$-azide, $300 \mu \mathrm{M}$ propranolol, $2 \mu \mathrm{M}$ rotenone, and $0.1 \%$ BSA.

\subsection{Chemicals}

All reagents were of analytical grade for research.

\subsection{Statistics}

The results are presented as a percentage of the controls \pm SEM from at least three independent experiments. When described, data obtained with different concentrations of OMW were compared with control (absence of OMW) by using one-way ANOVA with the Dunnett post-test. A value of $p<0.05$ was considered statistically significant. Data were analysed by using GraphPad Prism 4.0 (GraphPad Software). Some figures are records of individual experiments representative of three or more replicates.

\section{Results}

\subsection{Phenolic compounds analysis}

The phenolic compounds identification was made using measured retention times in comparison with external standards prepared with deionized water. Lucas et al. (2006) have reported that C. oleophila was able to assimilate as sole carbon and energy source some phenolic acids and this yeast strain was also able to fully decolorize mediums containing the diazo dye Reactive Black 5 . However, OMW treated with this yeast strain does not 
show any detectable decolorization. Furthermore, on comparing the results for measured phenols in control and those obtained after treatment with $C$. oleophila, no significant differences were observed (data not shown).

\subsection{Free fatty acid analysis}

Fatty acids analysis of treated and untreated OMWs does not show any significant difference in the fatty acid profiles. As far as small chain free fatty acids (C2-C6) are concerned, no differences were established between treated and untreated OMWs. Long chain free fatty acids (C16-C18) generally present in olive oil were also measured and the percentages are presented in Table 1.

\subsection{Condensed tannin analysis}

Tannins are assigned as benefic molecules due the popularity of some antioxidant activities observed on tannins isolated from fruits (e.g. grapes). However, like other phenols, not all tannins are benefic; some authors have reported disturbing effects of tannins on mitochondria (Spiridonov et al., 1997; Liu et al., 2004), like inhibition of succinate oxidation, loss of mitochondrial transmembrane potential, and mitochondria cytochrome $c$ release. The analysis of OMW treated with $C$. oleophila shows a decrease of about $20.3 \pm 4.8$ of the total condensed tannins when compared with untreated OMW.

\subsection{Effects of $O M W$ on mitochondrial respiration}

The effect of OMW on rat liver respiratory rates of state 4 (succinate alone), state 3 respiration (ADP-stimulated), and FCCP-stimulated respiration (uncoupled) was studied in the presence of succinate as respiratory substrate (Fig. 1). A 5-min treatment of the mitochondrial suspension $(1 \mathrm{mg}$ protein $/ \mathrm{mL})$ with $0.5-1.5 \%(\mathrm{v} / \mathrm{v})$ of untreated OMW results in a release of state 4 respiration, with an up to $200 \%$ increase in the $\mathrm{O}_{2}$ consumption when compared with the control. With higher concentrations of OMW $(2 \% \mathrm{v} / \mathrm{v})$ the stimulation was not so marked. Probably at the highest OMW concentration $(2 \% \mathrm{v} / \mathrm{v})$ some inhibitory

Table 1

Free fatty acids found in a sample of olive mill wastewater

\begin{tabular}{lr}
\hline Fatty acid & Mol. $(\%)$ \\
\hline C2 & $78.4 \pm 8.32$ \\
C3 & $1.37 \pm 0.04$ \\
C4 & $17.1 \pm 1.85$ \\
C6 & $0.221 \pm 0.02$ \\
C16 & $0.454 \pm 0.07$ \\
C16:1 & $0.086 \pm 0.01$ \\
C18 $18: 1$ & $0.061 \pm 0.01$ \\
C18:2 & $1.93 \pm 0.37$ \\
\hline
\end{tabular}

Data are the mean of three determinations \pm SD.

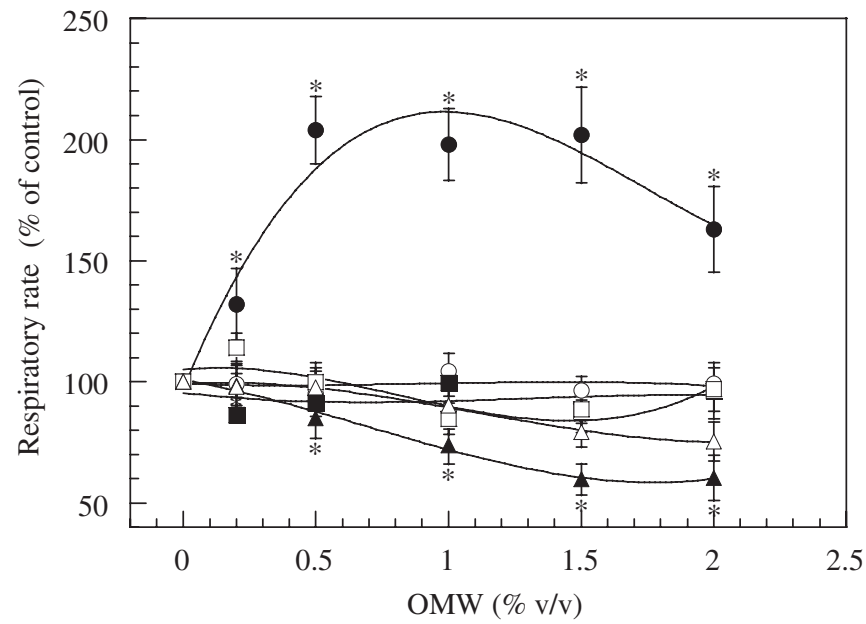

Fig. 1. Effect of untreated OMW (filled symbols) and treated OMW (open symbols) on respiratory rates of mitochondria. Mitochondria $(1 \mathrm{mg})$ were incubated, for $10 \mathrm{~min}$, in $1 \mathrm{~mL}$ of the respiratory standard medium in the presence of different OMW concentrations. $(\bullet, \bigcirc)$ State 4 respiration was initiated by the addition of $10 \mathrm{mM}$ succinate, $(\boldsymbol{\nabla}, \square)$ state 3 respiration energized by $10 \mathrm{mM}$ succinate was initiated by the addition of $1.5 \mathrm{mM}$ ADP, $(\boldsymbol{\Lambda}, \square)$ FCCP-uncoupled respiration in the presence of $10 \mathrm{mM}$ succinate was initiated by the addition of $1 \mu \mathrm{M}$ FCCP. ADP or FCCP was added $2 \mathrm{~min}$ after the initiation of state 4 respiration. Values are the means \pm SD of four to five independent experiments performed in duplicates. *Values statistically different from control $(p<0.05)$.

effect of the respiratory chain should acquire relevance. A 5-15 min treatment with treated OMW, at all tested concentrations, does not induce any significant alteration on the state 4 and 3 respirations. Furthermore, FCCPuncoupled respiration was merely decreased $15 \%$ at the maximum used concentration $(2 \% \mathrm{v} / \mathrm{v}$ treated OMW).

The initial stimulation on the respiratory state 4 rate is presumably caused by the membrane partition of some constituents of OMW, like free fatty acids and some other organic molecules, which can cause mitochondrial membrane permeabilization.

As a control we performed the assays described in Fig. 1 with a modification; first we exposed the mitochondria to a medium preimplemented with substrate and added OMW $5 \mathrm{~min}$ later. The purpose of this control was to verify whether the mitochondria pre-incubated with OMW prior to substrate addition resulted in an irreversible damage on the respiratory complexes, with a limitation in the maximal respiratory rates. From the results obtained, we can conclude that pre-incubation with OMW at $2 \%(\mathrm{v} / \mathrm{v})$ before the substrate addition does not cause any irreversible damage on the respiratory complexes, since 5-15 min after OMW had been added the effects became noticed (data not shown); the results obtained are the same whether the substrate is added before or after pre-incubation with OMW.

The inhibition observed in the uncoupled respiration was about $40 \%$ of the control. This inhibitory effect of OMW on uncoupled respiration reflects its interaction with the mitochondrial redox chain. State 3 respiration was not so significantly inhibited as it was observed in the 
uncoupled respiration. At the maximum concentration used in the assay $(2 \% \mathrm{v} / \mathrm{v})$, the inhibition was about $5 \%$ of the control.

\subsection{Effects of OMW on mitochondrial membrane potential}

The effects of OMW on the energization and phosphorylation capacities of mitochondria were investigated by following transmembrane potential $(\Delta \psi)$ developed by mitochondria upon succinate oxidation. After succinate addition, mitochondria developed a transmembrane potential of about $-212 \mathrm{mV}$ (Fig. 2). Untreated OMW highly depolarized the membrane potential but treated OMW was much less efficient in decreasing mitochondrial membrane potential.

When treated OMW was used, electrical membrane potential was only significantly decreased for an OMW concentration of $1.5 \%(\mathrm{v} / \mathrm{v})(11 \%$ of the control value). At maximum used concentration $(2 \% \mathrm{v} / \mathrm{v})$, the decrease was $21 \%$ relatively to the control, while at this same concentration the untreated OMW almost completely collapses the electrical membrane potential (Fig. 2).

\subsection{Enzymatic activities}

Studies regarding enzymatic activities of respiratory complexes II-V allowed us to identify mitochondrial respiratory chain components affected by OMW.

In the presence of untreated OMW $(1 \% \mathrm{v} / \mathrm{v})$, succinate dehydrogenase was significantly inhibited $(23 \%)$ while treated OMW did not induce any significant inhibition. For $2 \%(\mathrm{v} / \mathrm{v})$ OMW dilutions, succinate dehydrogenase activity was inhibited $47 \%$ and $23 \%$ for untreated and treated OMWs, respectively (Fig. 3).

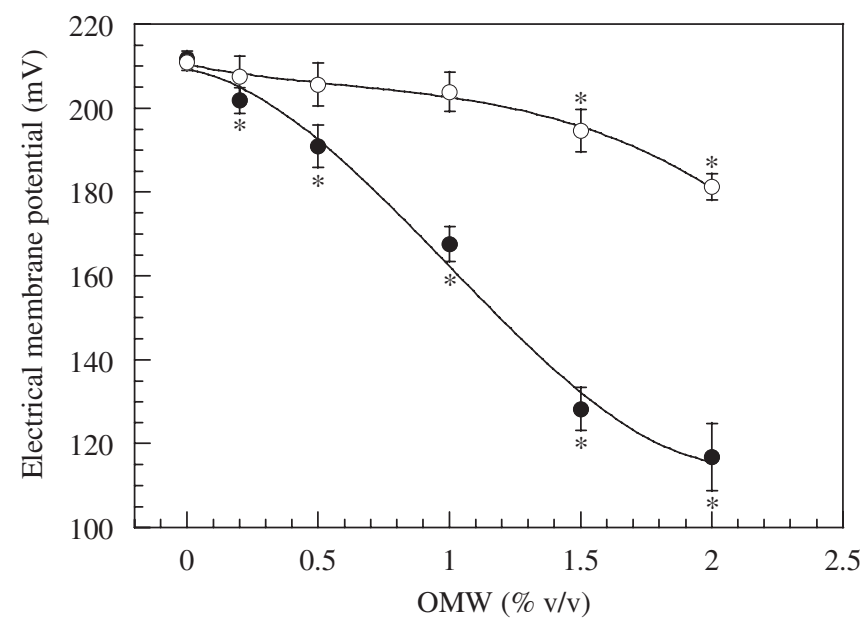

Fig. 2. Effect of untreated OMW (filled symbols) and treated OMW (open symbols) on mitochondrial membrane potential $(\Delta \psi)$ supported by succinate. Mitochondria $(1 \mathrm{mg})$ were added to the standard respiratory medium supplemented with $3 \mu \mathrm{M} \mathrm{TPP}{ }^{+}$. Maximum potential reached due to succinate $(10 \mathrm{mM})$ oxidation after 10 -min incubation with OMWs $(\bullet$, $\bigcirc)$. Values are the means \pm SD of five independent experiments performed in duplicates. *Values statistically different from control $(p<0.05)$.

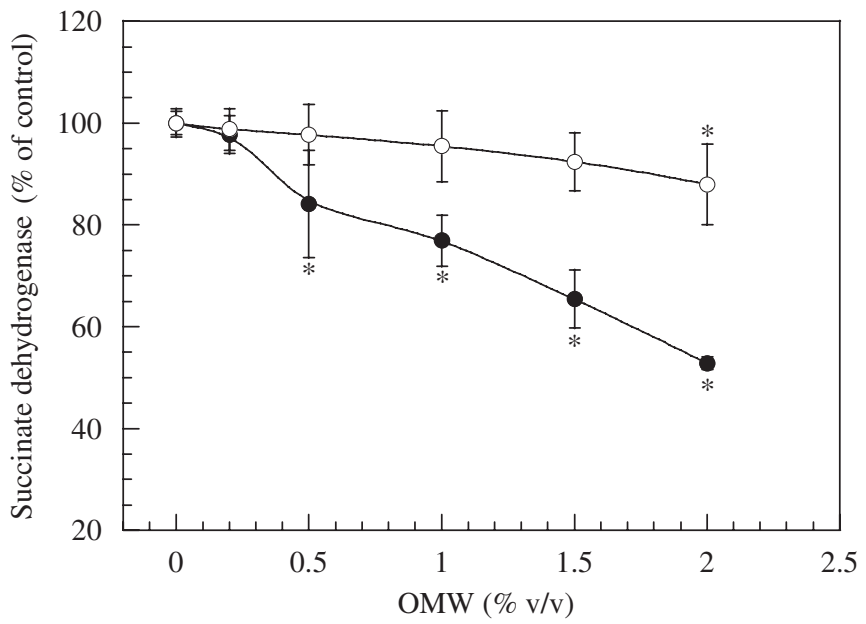

Fig. 3. Effect of untreated OMW (filled symbols) and treated OMW (open symbols) on the succinate dehydrogenase $(\bullet, \bigcirc)$. The activities were determined as described in the Materials and methods section. Values are the means $\pm \mathrm{SD}$ of four independent experiments performed in duplicates. *Values statistically different from control $(p<0.05)$.

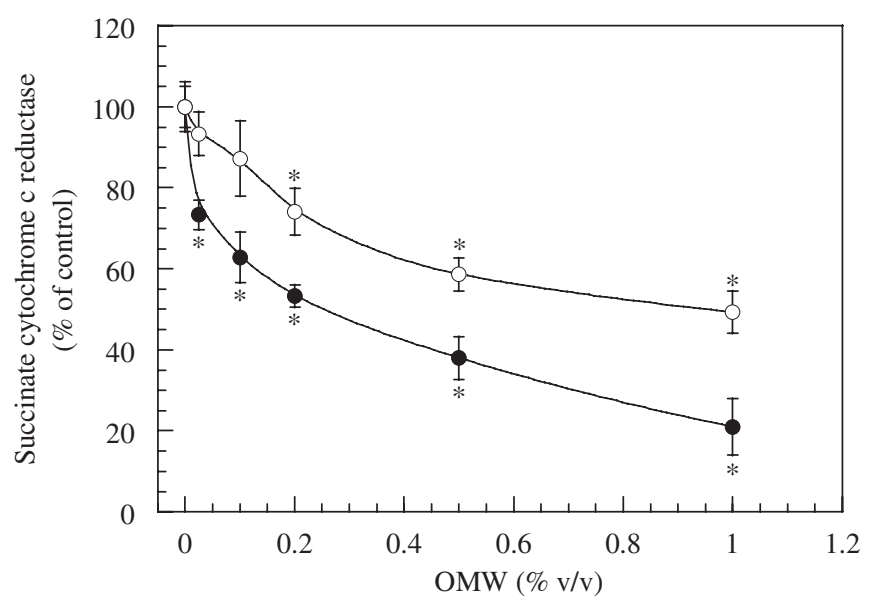

Fig. 4. Effect of untreated OMW (filled symbols) and treated OMW (open symbols) on the succinate cytochrome $c$ reductase $(\boldsymbol{\square}, \square)$. The activities were determined as described in the Materials and methods section. Values are the means $\pm \mathrm{SD}$ of four independent experiments performed in duplicates. ${ }^{*}$ Values statistically different from control $(p<0.05)$.

Succinate cytochrome $c$ reductase respiratory complex (Fig. 4) was much more sensitive to OMW action when compared with the results obtained for succinate dehydrogenase. At maximum used concentration $(1 \% \mathrm{v} / \mathrm{v})$ untreated OMW decreased the enzymatic activity $80 \%$ compared with the control, whereas the treated OMW decreased the activity about $50 \%$ (Fig. 4).

Cytochrome $c$ oxidase was not inhibited by any of the tested OMW (Fig. 5). Furthermore, a small, but significant, stimulation was observed for the lowest used concentration of untreated OMW.

Like it was observed for succinate dehydrogenase and succinate cytochrome $c$ reductase, ATPase activity was significantly inhibited by untreated OMW compared with 
treated OMW (Fig. 6). At maximum OMW used concentrations $(2 \% \mathrm{v} / \mathrm{v})$, the differences between the treated and untreated OMWs was nearly $24 \%$. ATP synthase was

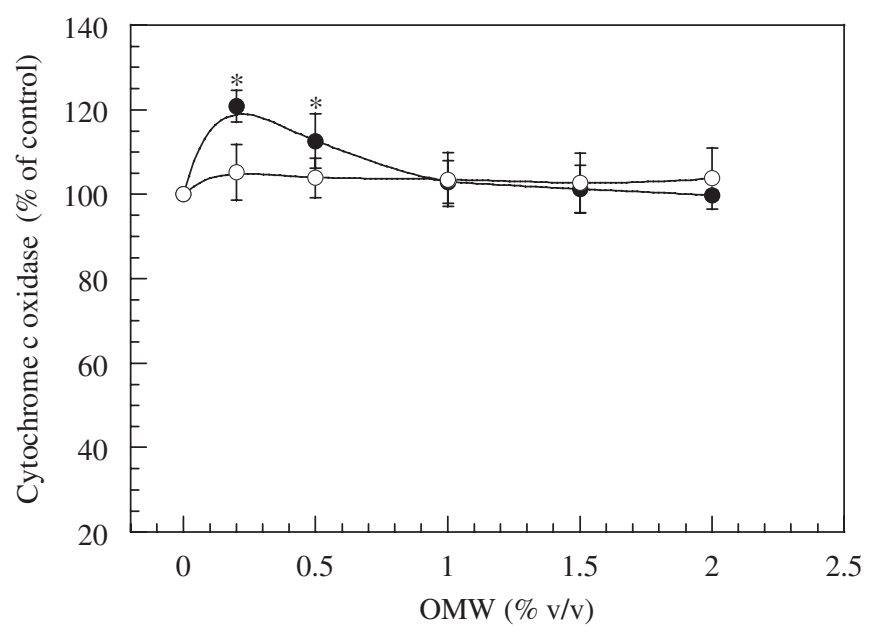

Fig. 5. Effect of untreated OMW (filled symbols) and treated OMW (open symbols) on the cytochrome $c$ oxidase $(\boldsymbol{\Lambda}, \square)$. The activities were determined as described in the Materials and methods section. Values are the means $\pm \mathrm{SD}$ of four independent experiments performed in duplicates. $*$ Values statistically different from control $(p<0.05)$.

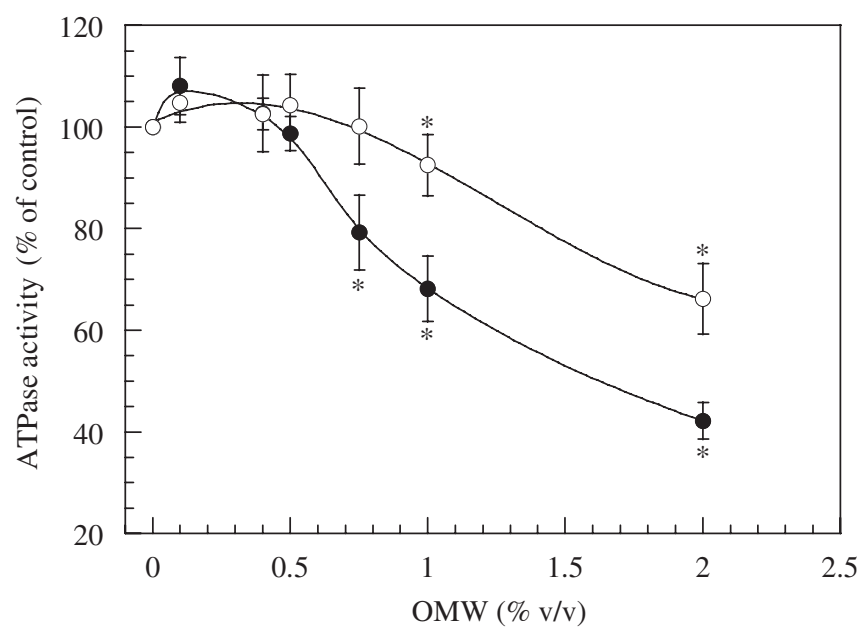

Fig. 6. Effect of untreated OMW (filled symbols) and treated OMW (open symbols) on rat liver mitochondrial ATPase $(\diamond, \diamond)$ activities. Experimental conditions are described in the Materials and methods section. Values are the means \pm SD of four independent experiments performed in duplicates. *Values statistically different from control $(p<0.05)$. also much more inhibited by untreated OMW than by treated OMW. Mitochondrial incubation with $1 \%(\mathrm{v} / \mathrm{v})$ of untreated OMW decreased the ATP-synthase activity about $78 \%$ compared with control, while treated OMW at the same concentration just inhibited by $37 \%$ in relation with the control. $\mathrm{IC}_{50}$ values obtained with treated and untreated OMWs are presented in Table 2 (Fig. 7).

\subsection{Proton-dependent mitochondrial swelling}

In order to demonstrate the protonophoric properties of OMW, we performed mitochondrial swelling in isosmotic $\mathrm{K}^{+}$-acetate medium in the presence of different concentrations of OMW (Fig. 8). The maximal valinomycindependent swelling stimulation was observed upon the addition of FCCP $(1 \mu \mathrm{M})$. Mitochondrial swelling occurs in the presence of a protonophore which enables the passage of protons from the matrix to the extramitochondrial reaction medium, allowing further acetate and $\mathrm{K}^{+}$influx (Nicholls, 1982). Therefore, valinomycin-induced swelling resulting from OMW is a consequence of a protonophoric action. OMW increases inner mitochondria membrane's permeability to protons (Fig. 8). Nevertheless, treated OMW was not so efficient.

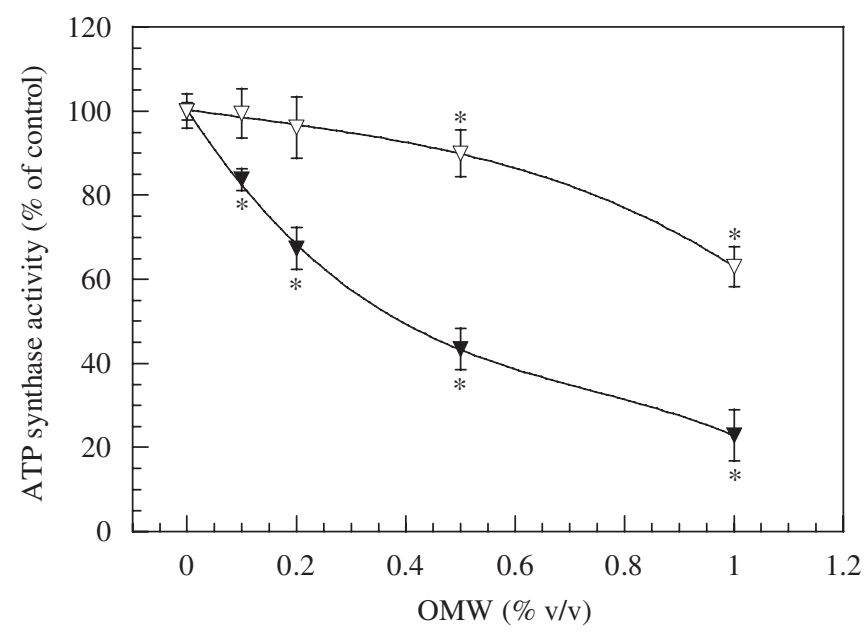

Fig. 7. Effect of untreated OMW (filled symbols) and treated OMW (open symbols) on rat liver mitochondrial ATP-synthase $(\boldsymbol{\nabla}, \nabla)$ activities. Experimental conditions are described in the Materials and methods section. Values are the means $\pm \mathrm{SD}$ of four independent experiments performed in duplicates. *Values statistically different from control $(p<0.05)$.

Table 2

Inhibitory results for different enzymes from mitochondrial respiratory chain after incubation with treated and untreated olive oil wastewaters

\begin{tabular}{|c|c|c|c|c|c|}
\hline OMW & $\begin{array}{l}\mathrm{SD} \\
\mathrm{IC}_{50} 5 \mathrm{~min}(\%)\end{array}$ & $\begin{array}{l}\mathrm{SCR} \\
\mathrm{IC}_{50} 5 \mathrm{~min}(\%)\end{array}$ & $\begin{array}{l}\mathrm{COX} \\
\mathrm{IC}_{50} 5 \min (\%)\end{array}$ & $\begin{array}{l}\text { ATPase } \\
\mathrm{IC}_{50} 5 \mathrm{~min}(\%)\end{array}$ & $\begin{array}{l}\text { ATP synthase } \\
\text { IC }_{50} 5 \mathrm{~min}(\%)\end{array}$ \\
\hline Untreated & 1.90 & 0.28 & \# & 1.65 & 0.39 \\
\hline Treated & $\#$ & 0.84 & \# & \# & $\#$ \\
\hline
\end{tabular}

$\mathrm{SD}$, succinate dehydrogenase; SCR, succinate cytochrome $c$ reductase; COX, cytochrome $c$ oxidase. \# values are out of range of the used concentrations. 


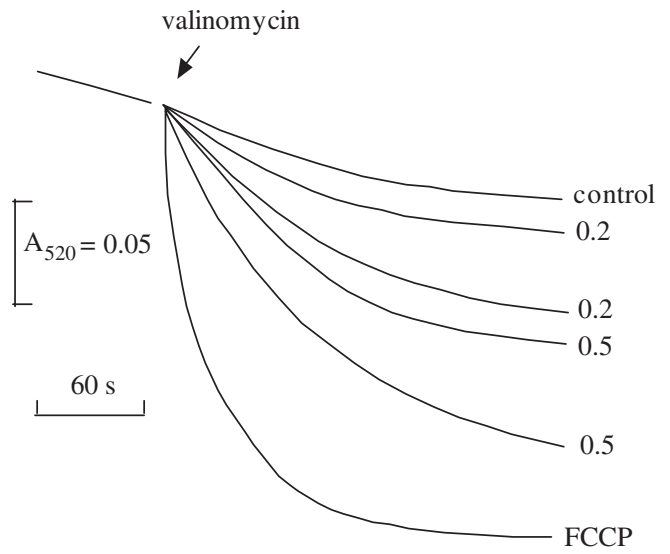

Fig. 8. Effect of untreated OMW and treated OMW on mitochondrial swelling. OMW was added at concentrations of $0.2 \%$ and $0.5 \%(\mathrm{v} / \mathrm{v}) / \mathrm{mg}$ mitochondrial protein. The control experiment was made in the absence of FCCP and OMW. Maximum swelling was obtained with FCCP $(1 \mu \mathrm{M})$. Valinomycin $(1 \mu \mathrm{M})$ was added where indicated. The traces are representative of a group of four independent experiments.

\section{Discussion}

Different olive wastes are known to contain high concentration of phenolic compounds (Fountoulakis et al., 2002; Lesage-Meessen et al., 2001) to whom several toxic effects are pointed out (Paixão et al., 1999; Martins et al., 2007). The degradation of phenolic compounds is considered as the limiting step in the biotreatment of OMW, since their natural breakdown is not easy (Fountoulakis et al., 2002). Long chain free fatty acids (C16 and $\mathrm{C} 18)$ are naturally occurring fats from olive fruits, which not only exhibit toxic effects towards microorganisms (Guilloux-Benatier et al., 1998) but also mitochondrial depolarization (Ray et al., 2002; Schönfeld et al., 2004).

Biological treatment of OMWs with $C$. oleophila was conducted in batch bioreactor cultures. C. oleophila grew well in sterilized and diluted OMW (75\%), without any addition of nutrients and any specific pre-treatment. During treatment no significant phenolic removal was observed. However, it is considered in this work that sterilized OMW should function as a model of phenolic rich wastewater, since sterilization may cause important physicochemical alterations on several compounds such as oxidation followed by precipitation (Fountoulakis et al., 2002).

From the HPLC chromatogram analysis, phenolic compounds present in OMW were not significantly metabolized by $C$. oleophila, although we may conclude that these compounds present no toxicity towards this species. Hamdi (1992) reported that phenols, responsible for OMW's black colour, present little toxicity and are not biodegradable. Other studies regarding the dephenolization of OMW, or production of valuable products, using as source an OMW effluent, used other C. oleophila yeast related species (Lanciotti et al., 2005; Fadil et al., 2003;
Ettayebi et al., 2003; D'Annibale et al., 2006; Papanikolaou et al., 2007). These works have proven that phenol removal from OMW by yeasts seems to be a strain-dependent process (Papanikolaou et al., 2007), since in similar conditions some yeast strains are able and others cannot grow in media with OMW, even when the amount of phenolic compounds is low. Previous reports (Lucas et al., 2006) showed that $C$. oleophila can use phenolics as carbon source when there is no other source, but is much more efficient when other easier source of carbon (as glucose) is available. In this work, and by the obtained results, the low metabolism of phenolic compounds may result from the fact that the isolate possesses many other sources of carbon and energy in the sterilized OMW. Tsioulpas et al. (2002) developed a new toxicity index, based on phenolic concentrations, and suggested (based on the same index) that although (Pleurotus sp.) treated OMW revealed to be less toxic, this decrease was not proportional to phenolics removal, as we found in our work.

As already reported by other authors, phenolic acids (e.g. ferulic acid) inhibit L-malate dehydrogenase and malic enzyme from soya bean mitochondria (Sert et al., 1998), $p$-coumaric acid inhibits plasmatic and mitochondrial monocarboxylate carrier and also mitochondrial respiration dependent on pyruvate oxidation (Lima et al., 2006). Mitochondrial proton $\mathrm{F}_{0}-\mathrm{F}_{1}$ ATPase/ATP synthase was also affected by polyphenolic acids (Zheng and Ramirez, 2000). However, considering the results obtained in this work, the toxicological effect of OMW previously reported (Martins et al., 2007) cannot be assigned to the effect of phenolic compounds. Instead, our results lead to the presence of condensed tannins as a possible cause for the deleterious effect observed on rat liver bioenergetics (Spiridonov et al., 1997; Liu et al., 2004), since treatment of OMW with $C$. oleophila has a reducing effect on tannins content. Again, in the above-mentioned report (Hamdi, 1992), it is suggested that, on the contrary to polyphenolic compounds, tannins are highly toxic, but biodegradable by some species. In our working conditions, the $C$. oleophila inoculums were not affected by tannins toxicity, and furthermore, they were able to somehow metabolize these compounds reducing their content in the samples. This seems to be the most important factor in reducing the toxic effect on mitochondrial bioenergetics.

Many works concerning OMW biodegradation can be found in the literature (Ahmadi et al., 2006; Di Gioia et al., 2001; Jaouani et al., 2005; Lanciotti et al., 2005), and although some perform toxicological evaluations of OMW after treatment (Dhouib et al., 2006; El Asli et al., 2005; Fiorentino et al., 2004; Isidori et al., 2005), these toxicological tests evaluate mainly the effects on seed germination.

Mitochondrion supports the energy-dependent regulation of many cell functions, namely intermediary metabolism, protein folding, ion regulation, cell motility, and cell proliferation (Wallace, 1999). Therefore, disruption of the coupling efficiency between oxidation and phosphorylation 
promotes large bioenergetic deficits leading to the loss of several vital functions both to the cell and the organism. OMW toxicity could then be monitored by the disturbances induced on mitochondrial functions.

In the present work, rat liver mitochondria were used as in vitro monitors to validate the effect of OMW treatment with $C$. oleophila on the OMW toxicity. Previous work (Martins et al., 2007) by our group clearly demonstrate OMW's ability to interact with mitochondrial oxidative phosphorylation. Alterations of basic mitochondrial functions were detected by changes induced in mitochondrial respiration and membrane energization $(\Delta \psi)$.

The results obtained in this study clearly show that the treatment of OMW with C. oleophila considerably decreased the injurious effect of OMW on the mitochondrial electrical membrane potential. In fact, at tested concentrations, treated OMW has no significant effect on mitochondrial respiration, and the effects on mitochondrial electrical membrane potential appear only for dilutions up to $1.5 \%$. Furthermore, untreated OMW at $0.2 \%$ induced a small, but significant, decrease on the electrical membrane potential, and at $1.5 \%$ dilutions almost completely collapsed the electrical membrane potential. OMW have many free fatty acids (Filidei et al., 2003; Procida and Ceccon, 2006). These fats are originally from the olive oil itself and others from microbial metabolism, which can significantly contribute to the observed effect on the transmembrane potential since long chain free fatty acid can easily disrupt the inner mitochondrial membrane. However, the differences observed in the effect of the two OMWs could not be attributed to free fatty acids, since no differences were observed on the composition and content between treated and untreated OMW. Papanikolaou and Aggelis (2003), as well as other reports, have proven the existence in Yarrowia lipolytica and other related strains of carrier systems for fatty acids (one for $\mathrm{C}_{12}$ and $\mathrm{C}_{14}$ fatty acids, and other for $\mathrm{C}_{16}$ and $\mathrm{C}_{18}$ fatty acids). According to these reports, these strains, specially $Y$. lipolytica, preferably incorporates from the medium unsaturated fatty acids. Furthermore, Papanikolaou and Aggelis (2003) suggested the use of fatty wastewaters as growth medium to produce "new" pre-determined lipids by selected $Y$. lipolytica strains. To the best of our knowledge, there are no reports concerning $C$. oleophila ability to selectively remove free fatty acids from an oleaginous mixture. Nevertheless, $C$. oleophila proved to be a well-adapted species in OMW. The aim of our study could not determine our isolate ability to use fatty acids, but is an issue to be studied in further works.

Comparing the effects of untreated and treated OMW on the enzymes of mitochondrial respiratory chain, it is clear that the previous treatment with $C$. oleophila was very significant in reducing the inhibitory effect in some enzymatic activities. However, the effect was not similar for all the tested enzymes. Untreated OMW shows a very low $\mathrm{IC}_{50}$ for succinate cytochrome $c$ reductase $(0.28)$ and ATP synthase (0.39) (Table 2). These values are lower than that of those reported for other toxicity tests with $D$. magna and $V$. fischeri (Gotsi et al., 2005; Paixão et al., 1999). The inhibitory effect on ATP-synthase activity may result from a direct inhibition of some OMW compound on the complex, which was not tested (ATPase activity); by inhibitory effects on other respiratory chain complexes, as seen by the results; or by changes in electrical membrane potential, also observed in the results. On the other hand, the observed effect in succinate cytochrome $c$ reductase is a consequence of direct inhibition of the enzyme (complexes II and III). We so believe that this enzyme could be considered as a target of OMW inhibition effects, especially caused by tannins present in these wastewaters, since only the variation of these compounds presented significance between $C$. oleophila treated and untreated OMWs.

\section{Conclusions}

Ultimately, condensed tannins could, probably, interact with mitochondrial membranes, causing an alteration on the surface charge density and a disturbance in the physicochemical and structural properties of the inner membrane. These would then lead to a disturbance in the electron delivery between redox complexes and, additionally, to an increase of the permeability to protons.

In conclusion, OMW treatment with $C$. oleophila shows a significant decrease in the interference with the mitochondrial bioenergetics; the observed decrease is not connected to the presence of free fatty acids or phenolic acid compounds on the OMW, since no differences were observed with the treatment. However, the differences could be related with diminishing of some mitochondrial active tannins. Considering the potential effect of some of these compounds on the rat liver bioenergetics, we can consider that the decrease observed on the OMW after C. oleophila treatment could probably be explained by the degradation of this kind of compounds. From these results we can also conclude that $C$. oleophila could be efficient in decolorizing some commercial dyes but in complex matrixes like OMW the results were not totally satisfactory.

\section{Acknowledgments}

This study was fully supported by the Foundation for Science and Technology (FCT) through the financial support attributed to the Center of Animal and Veterinary Science (CECAV) from the University of Trás-os-Montes and Alto Douro, Portugal.

Disclaimer. The experiments were carried out in accordance with the National (DL 129/92; DL 197/96; P 1131/97) and European Convention for the Protection of Animals Used for Experimental and Other Scientific Purposes and related European Legislation (OJ L 222, 24.8.1999). 


\section{References}

Aggelis, G., Iconomou, D., Christou, M., Bokas, D., Kotzailias, S., Christou, G., Tsagou, V., Papanikolaou, S., 2003. Phenolic removal in a model olive oil mill wastewater using Pleurotus ostreatus in bioreactor cultures and biological evaluation of the process. Water Res. 37, 3897-3904.

Ahmadi, M., Vahabzadeh, F., Bonakdarpour, B., Mehranian, M., Mofarrah, E., 2006. Phenolic removal in olive oil mill wastewater using loofah-immobilized Phanerochaete chrysosporium. World J. Microbiol. Biotechnol. 22, 119-127.

Amaral, C., Lucas, M., Sampaio, A., Peres, J.A., Dias, A.A., TorresPereira, J.M., 2005. Degradação de compostos fenólicos por leveduras isoladas de águas ruças. Rev. Ciênc. Agrar. 28, 209-223.

Benitez, F.J., Beltran-Heredia, J., Acero, J.L., Pinilla, M.L., 1997. Simultaneous photodegradation and ozonation plus UV radiation of phenolic acids-major pollutants in agro-industrial wastewaters. J. Chem. Technol. Biotechnol. 70, 253-260.

Benitez, F.J., Beltran-Heredia, J., Torregrosa, J., Acero, J.L., 1999. Treatment of olive mill wastewaters by ozonation, aerobic degradation and the combination of both treatments. J. Chem. Technol. Biotechnol. 74, 639-646.

Borja, R., Alba, J., Banks, C.J., 1995a. Activated-sludge treatment of wash waters derived from the purification of virgin olive oil in a new manufacturing process. J. Chem. Technol. Biotechnol. 64, 25-30.

Borja, R., Banks, C.J., Alba, J., 1995b. A simplified method for determination of kinetic parameters to describe the aerobic biodegradation of two important phenolic constituents of olive mill wastewater by a heterogeneous microbial culture. J. Environ. Sci. Health A 30 (3), 607-626.

Brautigan, D.L., Ferguson-Miller, S., Margoliash, E., 1978. Mitochondrial cytochrome c: preparation and activity of native and chemically modified cytochrome c. Methods Enzymol. 53, 128-164.

Cossu, R., Blakey, N., Cannas, P., 1993. Influence of co-disposal of municipal solid waste and olive vegetation water on the anaerobic digestion of a sanitary landfill. Water Sci. Technol. 27, 261-271.

Dhouib, A., Aloui, F., Hamad, N., Sayadi, S., 2006. Pilot-plant treatment of olive mill wastewaters by Phanerochaete chrysosporium coupled to anaerobic digestion and ultrafiltration. Process Biochem. 41, $159-167$.

Di Gioia, D., Bertin, L., Fava, F., Marchetti, L., 2001. Biodegradation of hydroxylated and methoxylated benzoic, phenylacetic and phenylpropenoic acids present in olive mill wastewaters by two bacterial strains. Res. Microbiol. 152, 83-93.

D’Annibale, A., Sermanni, G.G., Federici, F., Petruccioli, M., 2006. Olive-mill wastewaters: a promising substrate for microbial lipase production. Bioresource Technol 97 (15), 1828-1833.

Eckert, A., Keil, U., Marques, C.A., Bonert, B., Frey, C., Schüssel, K., Müller, W.E., 2003. Mitochondrial dysfunction, apoptotic cell death, and Alzheimer's disease. Biochem. Pharmacol. 66, 1627-1634.

El Asli, A., Errachidi, F., Bennisse, R., Qatibi, A.I., Errami, M., 2005. Effect of cell immobilization on the treatment of olive mill wastewater by a total phenols, acetic acid and formic acid degrading bacterium strain. Grasas Aceites 56, 116-120.

Ettayebi, K., Errachidi, F., Jamai, L., Tahri-Jouti, M.A., Sendide, K., Ettayebi, M., 2003. Biodegradation of polyphenols under met with immobilized Candida tropicalis abolic induction. FEMS Microbiol. Lett. 223 (2), 215-219.

Fadil, K., Chahlaoui, A., Ouahbi, A., Zaid, A., Borja, R., 2003. Aerobic biodegradation and detoxification of wastewaters from the olive oil industry. Int. Biodeterior. Biodegrad. 51, 37-41.

Filidei, S., Masciandaro, G., Ceccanti, B., 2003. Anaerobic digestion of olive oil mill effluents: evaluation of wastewater organic load and phytotoxicity reduction. Water Air Soil Pollut. 145, 79-94.

Fiorentino, A., Gentili, A., Isidori, M., Lavorgna, M., Parrella, A., Temussi, F., 2004. Olive oil mill wastewater treatment using a chemical and biological approach. J. Agric. Food Chem. 52, 5151-5154.
Fountoulakis, M.S., Dokianakis, S.N., Kornaros, M.E., Aggelis, G.G., Lyberatos, G., 2002. Removal of phenolics in olive mill wastewaters using the white-rot fungus Pleurotus ostreatus. Water Res. 36, 4735-4744.

Gazzoti, P., Malmstrom, K., Crompton, M., 1979. Membrane Biochemistry. A Laboratory Manual on Transport and Bioenergetics. Springer, New York.

Gharsallah, N., Labat, M., Aloui, F., Sayadi, S., 1999. The effect of Phanerochaete chrysosporium pretreatment of olive mill wastewaters on anaerobic digestion. Resour. Conserv. Recycling 27, 187-192.

Gornall, A.G., Bardawill, C.J., David, M.M., 1949. Determination of serum proteins by means of the biuret. J. Biol. Chem. 177, 751-766.

Gotsi, M., Kalogerakis, N., Psillakis, E., Samaras, P., Mantzavinos, D., 2005. Electrochemical oxidation of olive oil mill wastewaters. Water Res. 39, 4177-4187.

Guilloux-Benatier, M., Le-Fur, Y., Feuillat, M., 1998. Influence of fatty acids on the growth of wine microorganisms Saccharomyces cerevisiae and Oenococcus oeni. J. Ind. Microbiol. Biotechnol. 20, 144-149.

Hamdi, M., 1992. Toxicity and biodegradability of olive mill wastewaters in batch anaerobic-digestion. Appl. Biochem. Biotechnol. 37, 155-163.

Isidori, M., Lavorgna, M., Nardelli, A., Parrella, A., 2005. Model study on the effect of 15 phenolic olive mill wastewater constituents on seed germination and Vibrio fischeri metabolism. J. Agric. Food Chem. 53, 8414-8417.

Jaouani, A., Guillen, F., Penninckx, M.J., Martinez, A.T., Martinez, M.J., 2005. Role of Pycnoporus coccineus laccase in the degradation of aromatic compounds in olive oil mill wastewater. Enzyme Microb. Technol. 36, 478-486.

Khoufi, S., Aloui, F., Sayadi, S., 2006. Treatment of olive oil mill wastewater by combined process electro-Fenton reaction and anaerobic digestion. Water Res 40, 2007-2016.

Knobeloch, L.M., Blondin, G.A., Harkin, J.M., 1990. Use of submitochondrial particles for prediction of chemical toxicity in man. Bull. Environ. Contam. Toxicol. 44, 661-668.

Lanciotti, R., Gianotti, A., Baldi, D., Angrisani, R., Suzzi, G., Mastrocola, D., Guerzoni, M.E., 2005. Use of Yarrowia lipolytica strains for the treatment of olive mill wastewater. Bioresour. Technol. 96, 317-322.

Lesage-Meessen, L., Navarro, D., Maunier, S., Sigoillot, J.C., Lorquin, J., Delattre, M., Simon, J.L., Asther, M., Labat, M., 2001. Simple phenolic content in olive oil residues as a function of extraction systems. Food Chem. 75, 501-507.

Lima, L.C.N., Buss, G.D., Ishii-Iwamoto, E.L., Salgueiro-Pagadigorria, C., Comar, J.F., Bracht, A., Constantin, J., 2006. Metabolic effects of $p$-coumaric acid in the perfused rat liver. J. Biochem. Mol. Toxicol. 20, $18-26$.

Liu, M.J., Wang, Z., Li, H.X., Wu, R.C., Liu, Y.Z., Wu, Q.Y., 2004. Mitochondrial dysfunction as an early event in the process of apoptosis induced by woodfordin I in human leukemia K562 cells. Toxicol. Appl. Pharmacol. 194 (2), 141-155.

Lucas, M.S., Amaral, C., Sampaio, A., Peres, J.A., Dias, A.A., 2006. Biodegradation of the diazo dye Reactive Black 5 by a wild isolate of Candida oleophila. Enzyme Microb. Technol. 39, 51-55.

Madeira, V.M.C., Antunes-Madeira, M.C., Carvalho, A.P., 1974. Activation energies of the ATPase activity of sarcoplasmic reticulum. Biochem. Biophys. Res. Commun. 58, 897-904.

Martins, F., Gomes-Laranjo, J., Amaral, C., Peixoto, F., 2007. Evaluation of olive oil mill wastewaters acute toxicity: a study on the mitochondrial bioenergetics. Ecotoxicol. Environ. Saf., in press, doi:10.1016/j.ecoenv.2007.05.008.

Nicholls, D.G., 1982. Bioenergetics. An Introduction to the Chemiosmotic Theory. Academic Press, London.

Paixão, S.M., Mendonca, E., Picado, A., Anselmo, A.M., 1999. Acute toxicity evaluation of olive oil mill wastewaters: a comparative study of three aquatic organisms. Environ. Toxicol. 14, 263-269.

Papanikolaou, S., Aggelis, G., 2003. Selective uptake of fatty acids by the yeast Yarrowia lipolytica. Eur. J. Lipid Sci. Technol. 105, 651-655. 
Papanikolaou, S., Galiotou-Panayotou, M., Fakas, S., Komaitis, M., Aggelis, G., 2007. Citric acid production by Yarrowia lipolytica cultivated on olive-mill wastewater-based media. Bioresour. Technol. doi:10.1016/j.biortech.2007.05.005.

Peixoto, F., 2005. Comparative effects of the roundup and glyphosate on mitochondrial oxidative phosphorylation. Chemosphere 61, 1115-1122.

Pinto, G., Pollio, A., Previtera, L., Temussi, F., 2002. Biodegradation of phenols by microalgae. Biotechnol. Lett. 24, 2047-2051.

Porter, L.J., 1986. Number-Average and Weight-Average MolecularWeights for Some Proanthocyanidin Polymers (Condensed Tannins). Aust J Chem 39 (4), 557-562.

Procida, G., Ceccon, L., 2006. Gas chromatographic determination of free fatty acids in olive mill waste waters. Anal. Chim. Acta 561, $103-106$.

Ray, J., Noll, F., Daut, J., Hanley, P.J., 2002. Long-chain fatty acids increase basal metabolism and depolarize mitochondria in cardiac muscle cells. Am. J. Physiol. Heart Circ. Physiol. 282, H1495-H1501.

Schönfeld, P., Kahlert, S., Reiser, G., 2004. In brain mitochondria the branched-chain fatty acid phytanic acid impairs energy transduction and sensitizes for permeability transition. Biochem. J. 383, 121-128.

Sert, M.A., Ferraresi, M.L.L., Bernadelli, Y.R., Kelmer-Bracht, A.M., Bracht, A., Ishii-Iwamoto, E.L., 1998. Effects of ferulic acid on L-malate oxidation in isolated soybean mitochondria. Biol. Plant. 40 , $345-350$.
Singer, T.P., 1974. Determination of the activity of succinate, NADH, choline and glycerophosphate dehydrogenases. Methods Biochem. Anal. 22, 123-175.

Spiridonov, N.A., Arkhipov, V.V., Foigel, A.G., Tolkachev, O.N., Sasov, S.A., Syrkin, A.B., Tolkachev, V.N., 1997. The cytotoxicity of Chamaenerium angustifolium L. Scop. and Hippophae rhamnoides L. tannins and their effect on mitochondrial respiration. Eksp. Klin. Farmakol. 60 (4), 60-63.

Tisdale, H.D., 1967. Preparation and properties of succinic-cytochrome $c$ reductase (complex II and III). Methods Enzymol. 10, 213-215.

Tsioulpas, A., Dimou, D., Iconomou, D., Aggelis, G., 2002. Phenolic removal in olive oil mill wastewater by strains of Pleurotus spp. in respect to their phenol oxidase (laccase) activity. Bioresour. Technol. $84,251-257$.

Tuck, K.L., Hayball, P.J., 2002. Major phenolic compounds in olive oil: metabolism and health effects. J. Nutr. Biochem. 13, 636-644.

Vitolo, S., Petarca, L., Bresci, B., 1999. Treatment of olive oil industry wastes. Bioresour. Technol. 67, 129-137.

Wallace, D.C., 1999. Mitochondrial diseases in man and mouse. Science $283,1482-1488$

Wallace, K.B., Eells, J.T., Madeira, V.M., Cortopassi, G., Jones, D.P., 1997. Mitochondria-mediated cell injury. Symposium overview. Fundam. Appl. Toxicol. 38 (1), 23-37.

Zheng, J., Ramirez, V.D., 2000. Inhibition of mitochondrial proton F0F1-ATPase/ATP synthase by polyphenolic phytochemicals. Br. J. Pharmacol. 130, 1115-1123. 